\title{
The Spot Weldability of Carbon Steel Sheet
}

\author{
A. M. Al-Mukhtar ${ }^{1,2}$ and Q. Doos ${ }^{3}$ \\ ${ }^{1}$ Faculty of Geosciences and Geoengineering, Technische Universität Bergakademie Freiberg, Gustav-Zeuner-Straße 12, \\ 09599 Freiberg, Germany \\ ${ }^{2}$ Baghdad University, Al-Khwarizmi College of Engineering, University of Baghdad, Baghdad, Iraq \\ ${ }^{3}$ Baghdad University, College of Engineering, Baghdad, Iraq \\ Correspondence should be addressed to A. M. Al-Mukhtar; almukhtar@uni.de
}

Received 12 May 2013; Revised 25 August 2013; Accepted 5 September 2013

Academic Editor: Daolun Chen

Copyright (C) 2013 A. M. Al-Mukhtar and Q. Doos. This is an open access article distributed under the Creative Commons Attribution License, which permits unrestricted use, distribution, and reproduction in any medium, provided the original work is properly cited.

\begin{abstract}
The specimens of thickness $0.8 \mathrm{~mm}$ carbon steel number 1.8902 in a strip form were welded. The strips of lap joints and curved peeljoints configurations have been welded. The welding parameters such as weld current and weld time have been investigated. The relation between the weld area and the joint strength properties has been presented. The obtained results were showing that the weld joint strength and the molten area (weld nugget volume) highly increase with the increasing of weld current. Therefore, the correlation between the maximum load (joint strength) and area has been given. The reliable weldability under the tensile and shearing loading was considered. Therefore, the new limits of weldability have been presented to consider these two types of loading. Moreover, the experimental results were compared with the empirical relations that consider the sheet thickness only.
\end{abstract}

\section{Introduction}

Resistance spot welding (RSW) is the most widely common method used for joining structures and plates of different materials. This is because different joint configurations can be made. The other advantage is the ability of machine automatization. Therefore, the desired reliability of these joints can be made. Nevertheless, up to date, more works are needed to investigate the materials, welding ability and the reliability of these joints under different loading.

However, carbon steel 1.8902 has been used in the automotive and industrial application; the weldability of carbon steel; 1.8902 has been little investigated. The easy producing of sound spot welds by the convention tensile tests has been determined in different works [1-6]. The weld strength and weld nugget area that are related to the spot-welding variables were investigated. In most cases, good spot-welding practice requires three parameters that have to be controlled, namely, current, time, and electrode pressure [3].

Welding current passes through the joint interface to provide the required heat for melting due to the gap resistance. The increase in current to critical limits would rapidly increase in weld nugget strength, due to the increasing of the weld nugget area of mild steel [7]. The effect of the atmosphere which improves the tensile-shearing strength was investigated for the RSW of titanium sheets [5]. The response of strength to increase in current is regular for the aluminum alloys spot welding [7]. Weld time is the second variable during which the current is allowed to flow. Weld time for RSW is usually computed by the number of cycles as recorded oscillographically. The convention electronic timers can be used also by the second and converted to cycle ( $1 \mathrm{sec}$ = 60 cycle). Reference [4] investigated only the optimum weld time for tensile peel and tensile shear joint of $1.2 \mathrm{~mm}$ galvanized chromate steel sheets. The variable resistance $(R)$ is influenced by the force applied (i.e., electrode pressure) through its effect on contact resistance $[8,9]$. The increases of the contact resistance will increase the rate of heat generation. Therefore, the electrode pressure influences the heating of the joint primarily by affecting the contact resistance [7]. In case the pressure automation was not available, the electrode diameter could play the same rule. In this study, a systematic testing has been carried out to conduct the spot 
TABLE 1: Chemical composition of steel \%.

\begin{tabular}{lcccccc}
\hline Steel designation & $\mathrm{C}$ & $\mathrm{Cr}$ & $\mathrm{Ni}$ & $\mathrm{Mn}$ & $\mathrm{Si}$ & $\mathrm{Fe}$ \\
\hline 16 GS (1.8902) & 0.15 & 0.3 & 0.3 & 2.2 & 0.2 & Rem. \\
\hline
\end{tabular}

TABLE 2: Mechanical properties.

\begin{tabular}{lccc}
\hline $\begin{array}{l}\text { Tensile strength } \\
(\mathrm{MPa})\end{array}$ & $\begin{array}{c}0.2 \% \text { offset yield } \\
\text { strengths }\end{array}$ & Elongation & $\begin{array}{c}\text { Reduction of } \\
\text { area }\end{array}$ \\
\hline 600 & $365 \mathrm{MPa}$ & $19 \%$ & $50 \%$ \\
\hline
\end{tabular}

weldability of carbon alloy steel (1.8902). This steel has been successfully welded with a common spot-fusion process. The microstructural examination was not conducted since the aim of this work is to describe the weldability of the material. Therefore, a structural performance of the joint has been presented under tensile and shear loads.

\section{Experimental Program}

A tensile test was conducted for the lap and peel specimens. The specimens were welded using an electrode tip $4 \mathrm{~mm}$ diameter. The effect of welding variables on the joint strength and weld area of the 1.8902 carbon steel has been categorized for both types of specimens [10]. The program includes tensile test experiments to determine the spot weldability of carbon steel under two different modes of stresses. The test procedure includes the following.

(1) A set of peel and lap specimens were welded under different welding condition (weld time and current). The electrode tip was $4 \mathrm{~mm}$.

(2) A static tensile test has been made to determine the joint strength. The maximum load is a major property from the design point of view, and the weld nugget area has been measured. According to the thickness, the maximum weld current $7.2 \mathrm{kA}$ was applied, where the expulsion can be observed. The samples joined at a lower welding current of $3.7 \mathrm{kA}$ will not have an enough weld size due to the smaller heat input.

2.1. Materials. The material employed in these testings consisted of a single sheet of carbon cold rolled steel (16 GS, $1.8902)$ with a nominal thickness $(0.8 \mathrm{~mm})$. No surface coating was applied. Tables 1 and 2 show the chemical composition and the mechanical properties, respectively.

2.2. Welding Equipment. The resistance spot welding equipment employed in this investigation was a standard foot operated rocker arm spot welding (Bay Kay) with transformer capacity $(15 \mathrm{kVA})$ and single phase (220 volt). Electrode was pure copper (RWMA class 1) which has a high thermal and electrical conductivity. Nevertheless, some mechanical properties are required. The dimensions were controlled by the machining process for the electrode tips. Originally, the electrodes were machined with a flat tip diameter of $4 \mathrm{~mm}$ and body diameter of $16 \mathrm{~mm}$, and the tip angles were $30^{\circ}$ truncated cones.
TABLE 3: The welding process parameters.

\begin{tabular}{lccc}
\hline $\begin{array}{l}\text { Weld time } \\
(\text { cycle })\end{array}$ & $\begin{array}{c}\text { Weld current } \\
(\mathrm{kA})\end{array}$ & $\begin{array}{c}\text { Electrode } \\
\text { pressure }(\mathrm{MPa})\end{array}$ & $\begin{array}{c}\text { Electrode force } \\
(\mathrm{N})\end{array}$ \\
\hline $15,30,45,60$ & $3.7,5.8,6.7,7.2$ & 129 & 1617 \\
\hline
\end{tabular}

The electrode tip diameter was selected according to the American Welding Society (AWS) relationship [11]:

$$
d_{\mathrm{el}}=0.1+2 t,
$$

where $d_{\mathrm{el}}$ is the electrode tip diameter (in) and $t$ is the sheet thickness (in). This relationship may not be useful for thinner thickness ranges between 0.131 and $0.51 \mathrm{~mm}$ and for the thickness ranges between 3.18 and $12.7 \mathrm{~mm}$ [11].

2.3. Welding Process. The welding process was carried out for the specimen in specific dimensions; see Figure 1. The sets of welding specimens were made at different weld variables; see Table 3. At first, the weld time and electrode force were kept constant and varying the weld current subsequently. Moreover, the electrode tip diameter was fixed. Therefore, different welds joint properties were obtained. Four welding times and currents were applied. Sixteen sets of specimens were made. Each set consists of three specimens for each time and current. Therefore, each point on the curves represents the average of three reading values. Electrode force was set to be constant at $1617 \mathrm{~N}$. Hence, for the electrode diameter of $4 \mathrm{~mm}$, the electrode pressure was proposed to be equal to $129 \mathrm{MPa}$.

2.4. Tensile and Shearing Testing. Static strength was measured using the conventional tensile shear lap specimens and peel specimens. Specimen details and testing methods were confirmed by the AWS practice [12]. All welds were tested in tensile shear using a conventional hydraulic tensile testing machine (Adamel Lhomrgy Dy. 25) model EG04. It was equipped with a digital readout for both load and extension. The available function of the machine is to maintain both the peak load and the weld strength $[7,13]$.

The lap shear specimen of two flat plates of $0.8 \mathrm{~mm}$ thickness with an overlapping distance of $25 \mathrm{~mm}$ was welded, see Figure 1(a). The geometry was approximated as closely as possible to pure shear made on the joint.

The peel mode specimen was subjected to a combined stress created by joining the specimen distances away from the loading plane; see Figure 1(b). The stresses were a tensile load combined with moment around the weld point. The behavior was closely approximated to pure tension [7]. The entire specimen dimensions were confirmed by AWS practice [11].

\section{Determination of Weldability}

The spot weldability for $0.8 \mathrm{~mm}$ carbon steel was determined in the form of Lobe curves. This curve is plotted as weld time versus weld current in one form of loading. It indicates the range of conditions in which satisfactory welds can 


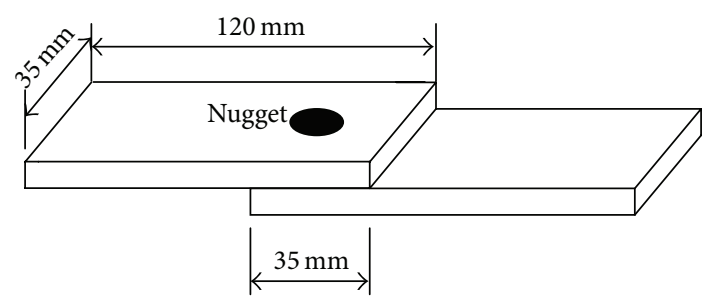

(a)

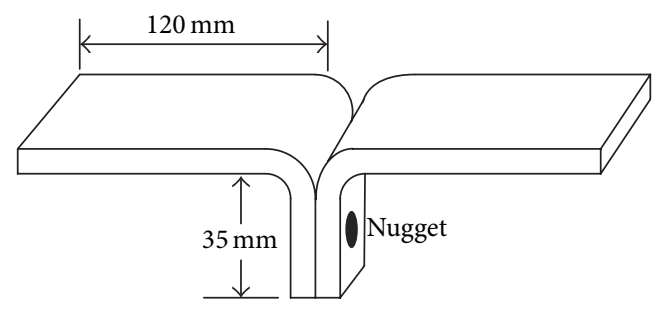

(b)

FIGURE 1: (a) Lap-shear tensile test specimen; (b) peel-tensile test specimen.

be obtained. Lobe curve will be obtained by performing the tensile test on specimens that welded under various conditions of welding time and current by varying weld times for a specified current. The limit can be found, and the curve can be established [7]. The specimens with a higher and lower tensile shear that are related to the heat input amount have been demonstrated as follows.

(1) The upper limit of the welding current range is generally regarded as the minimum current that causes expulsion.

(2) The lower limit can be established by determining $(2 / 3$ $\left.P_{\max }\right)$ at each time. The maximum breaking strength can be supported by the weld nugget and extending this value to intersect the $x$-axis of each time, in plots of load VS current which are obtained from lap and peel tests. Then, this value will be projected to obtain the minimum current from $x$-axis for each value of times.

(3) The first point on the left curve (lower bound) has joint strength $\left(2 / 3 P_{\max }\right)$. The second points of the right curve (upper bound) in which there is expulsion at the end of the welding zone.

(4) When the weld is made with current and/or time exceeding the upper limit in the Lobe curve, expulsion occurs and therefore is considered unacceptable. In contrast, welds which are made with current or time below the lower limit have insufficient size nuggets. Thus, it will be brittle and is likewise considered unacceptable.

Because the weldability also describes the joint strength, and since the weld nugget area determines the strength [14], the American Welding Society (AWS), American National Standards Institute (ANSI), and the Society of Automotive Engineers (SAE) have recommended (2) to estimate the weld nugget area $\left(d_{n}\right)$ with respect to the electrode diameter as follows:

$$
d_{n}=4(t)^{0.5} .
$$

Nevertheless, according to [12], the fused area should be at least as follows:

$$
d_{n}=0.8(t)^{0.5},
$$

where $t$ is the thickness of the thinnest of the two pieces. Therefore, the optimum nugget area for a certain electrode diameter can be estimated.

\section{Results and Discussion}

4.1. Lap-Test Results. In this test, the specimen of spot weld was submitted to combined shear stresses and a certain amount of through thickness tensile stresses. The experimental results focus on the current and time effects.

4.1.1. Effect of Weld Current and Weld Time. The welding current has a major influence on the tensile and shearing strength, while the weld time and electrode diameter come after accordingly. The maximum stress was measured which indicated the joint strength. The joint strength and the weld nugget area increase with the increasing of the weld current up to the maximum value as shown in Figure 2. The results agree with [6]. The same behavior was obtained by increasing the weld time; see Figure 3. The result from [5] has shown that the increasing of the weld time and electrode force increases the tensile shearing strength, that is, weld area. Reference [5] also investigated the effect of Argon atmosphere on the tensile shearing strength.

A direct relationship between current, joint strength, and weld area agrees with the feature of the AWS curve [14]. The weld area increases rapidly with weld current, from low current levels until expulsion occurs at the higher current levels. A similar behavior occurs with the weld strength. Because the joint strength has been increased as the weld current and area are increasing. Then, the expulsion will reduce the fused metal. Hence, the enhancement in tensile shearing of the spot weld joint is attributed to the enlargements of the weld area. This result also agrees well with $[3,4,6]$.

Figures 2(b) and 3(b) show the comparison with (2) and (3). It was shown that the relation from AWS gives better estimation. However, these linear relationships do not consider the increasing of the area due to heat generation.

Welding with electrode diameter of $4 \mathrm{~mm}$ and low welding current (below $3.7 \mathrm{kA}$ ) will result in a smaller weld area. Since a shallow depth and indentation as well as smaller diameter are produced, the joint will withstand smaller load. Nevertheless, the weld area and joint strength will rapidly increase after the current of $5.8 \mathrm{kA}$. Normally, the maximum and minimum welding parameters are influenced by and dependent on the product geometry, machine type and design, and electrode materials and design. Therefore, the weldability investigation of a certain material in a production 


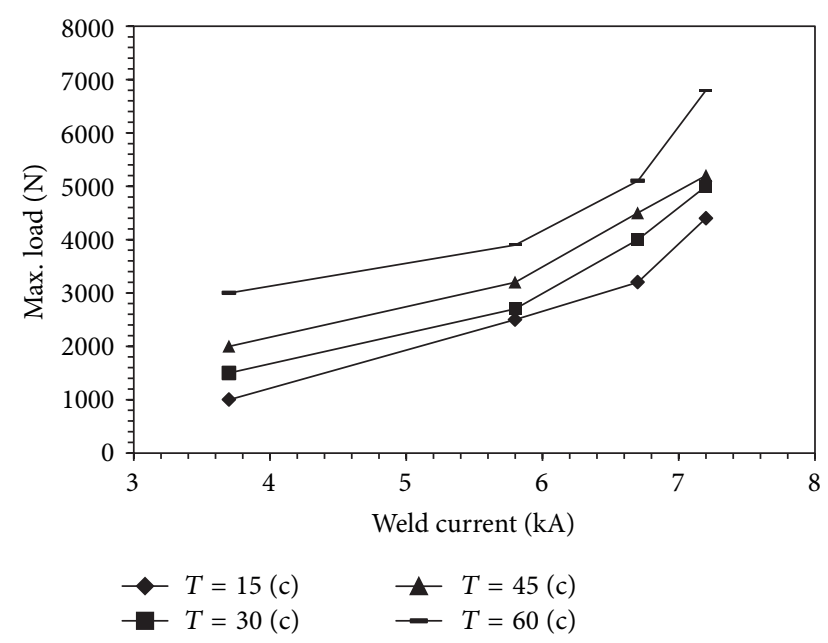

(a)

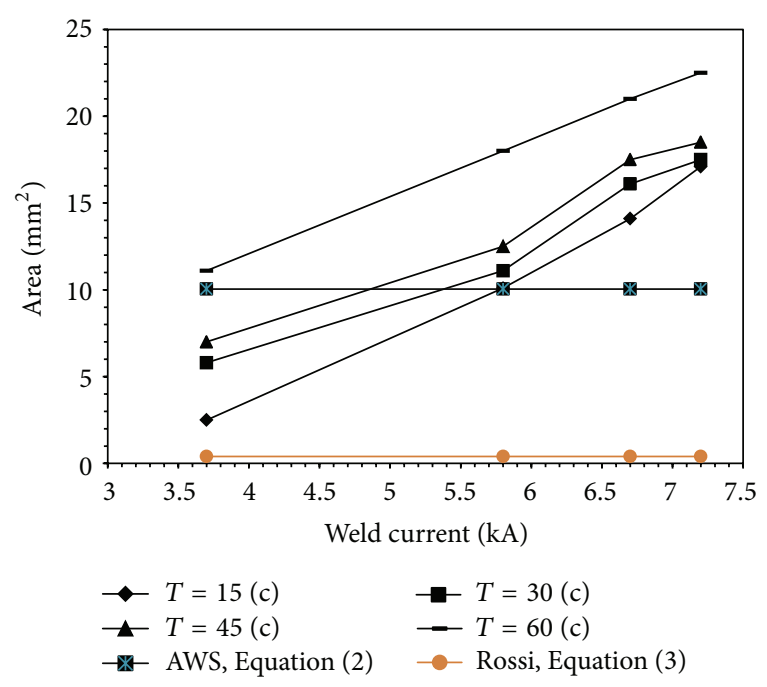

(b)

FIGURE 2: Effect of current of the lap joints, $d_{\mathrm{el}}=4 \mathrm{~mm}, t=0.8 \mathrm{~mm}$; (a) tensile strength; (b) weld nugget area.

line will be needed to get these entire factors in one hand. Nevertheless, the researchers have selected a certain couple of parameters for studying the weldability of metals.

4.2. Peel-Test Results. Due to the configuration of this specimen, a higher tensile stress will be developed over the spot weld. A significant torque arises, depending on the position of the weld point from the plain of applied load. Therefore, the tensile test results of this type of specimen show a low strength with large displacement. This result agrees well with those presented by $[4,9,14]$. The weld nugget will not support the applied load. Then, the failure occurs at a lower load as compared with lap joint, in which the nugget undergoes shear stress with little amount of torque around the nugget.

4.2.1. Effect of Weld Current and Weld Time. Again the weld area and joint strength increase with the welding current. But

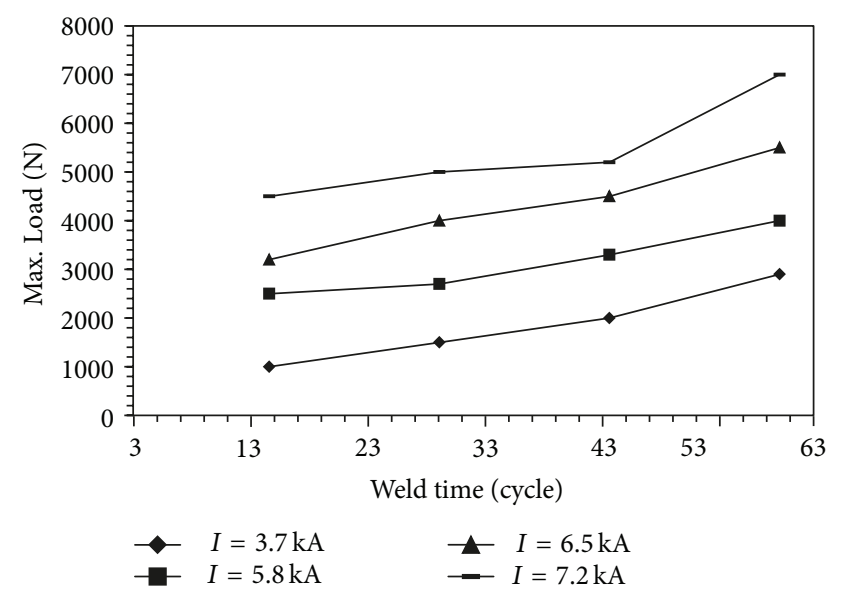

(a)

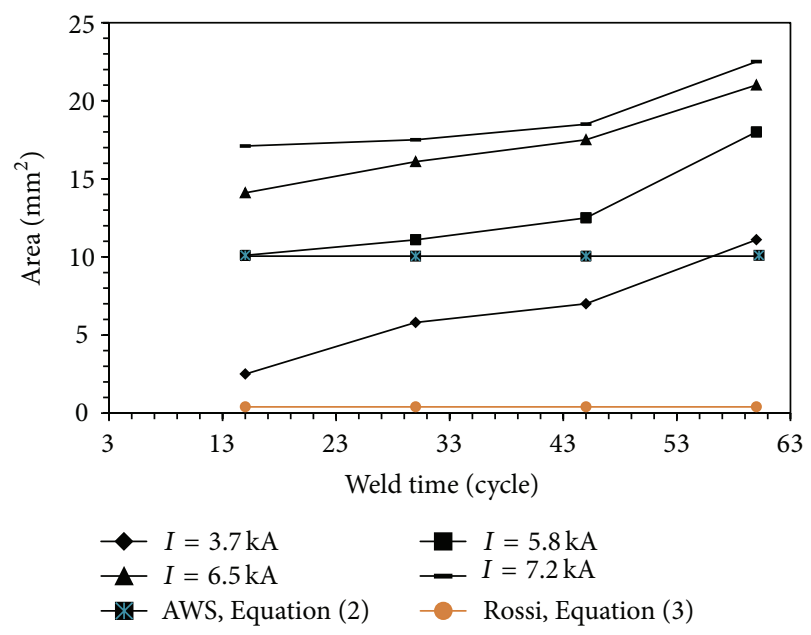

(b)

Figure 3: Effect of time of the lap joints, $d_{\mathrm{el}}=4 \mathrm{~mm}, t=0.8 \mathrm{~mm}$; (a) tensile strength; (b) weld nugget area.

lower values of joint strength were obtained as compared with the lap joint which agrees with [12]; see Figure 4. However, the area of weld nugget of the peel specimen is little higher than those measured for the lap joint [14].

The increasing of the welding time from the initial values causes an increasing in the weld nugget area which leads to the increasing of the joint strength; see Figure 5.

Again (3) and (2) give a lower value of weld nugget diameter according to the sheet thickness. It is to be emphasized that these values from (2) and (3) only represent minimum size that could be expected to carry the load for a specific thickness.

\section{Weldability Lobe Curve}

Different studies deal with spot welding effected parameters; see $[2-8,15]$. However, their objectives were to investigate the spot weldability, no determination of Lobe curves has been presented. Figure 6 shows the specific Lobe curve for carbon steel with nominal thickness of $0.8 \mathrm{~mm}$. No coating 


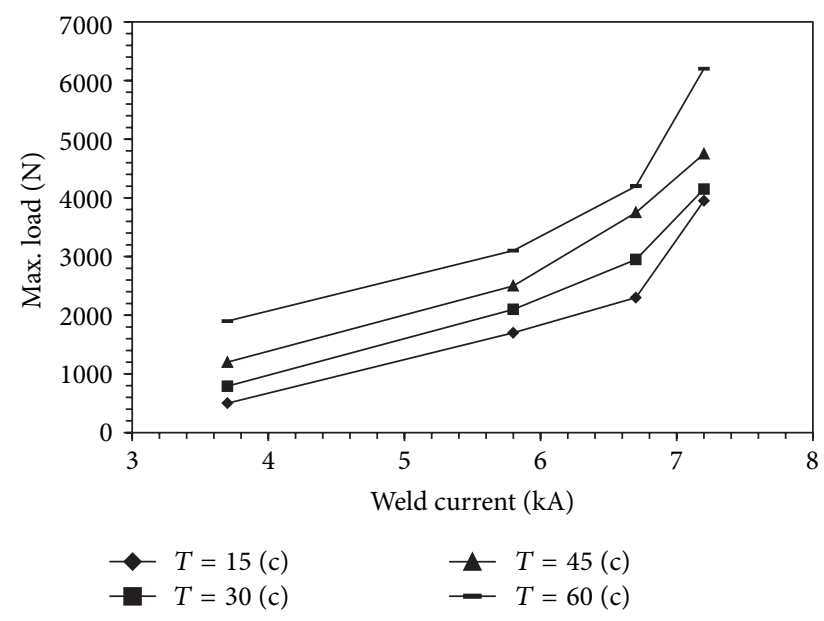

(a)

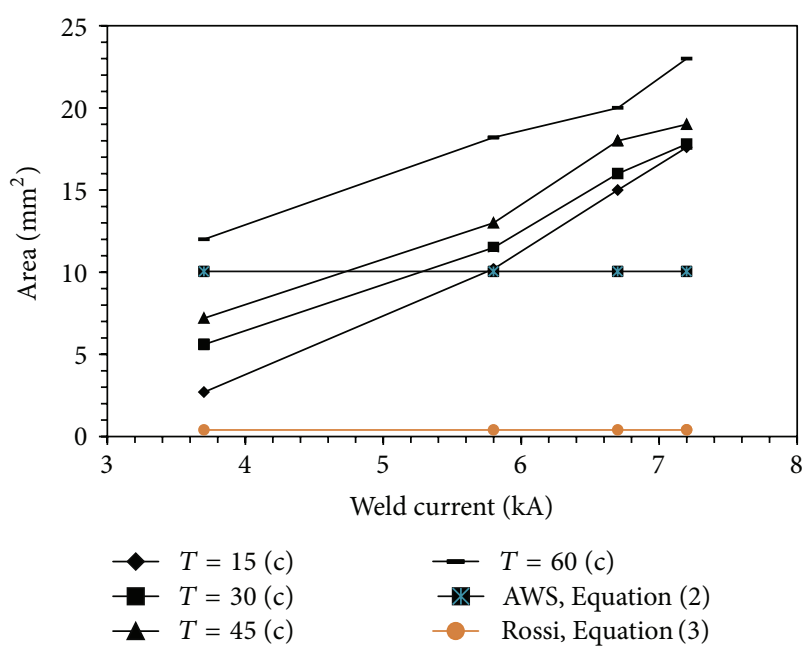

(b)

FIGURE 4: Effect of current of the peel joints; $d_{\mathrm{el}}=4 \mathrm{~mm}, t=0.8 \mathrm{~mm}$; (a) tensile strength; (b) weld nugget area.

was applied for the sheet surfaces. The brittle and expulsion limits are shown. The width of the acceptable welds can be changed according to the sheet thickness, material type, heat treatments, and surface conditions.

The produced weld area and strength have a polynomial relationship with the welding parameters for lap and peel joints, see (4), respectively, as shown in Figure 7. According to the upper and lower limits in Figure 7, the weldability has been estimated in a new vision. Therefore, the values between these two limits represent the general weldability and reliability under different loading type:

$$
\begin{aligned}
& {\left[\operatorname{Max} \cdot \operatorname{load}(N)=7.6609 \times \text { Area }^{2}\right.} \\
& +78.396 \times \text { Area }+882.1]_{\text {Shear,lap' }} \text {, } \\
& {\left[\operatorname{Max} . \operatorname{load}(N)=0.67\left[7.6609 \times \text { Area }^{2}\right.\right.} \\
& +78.396 \times \text { Area }+882.1]]_{\text {Tensile,peel }}{ }
\end{aligned}
$$

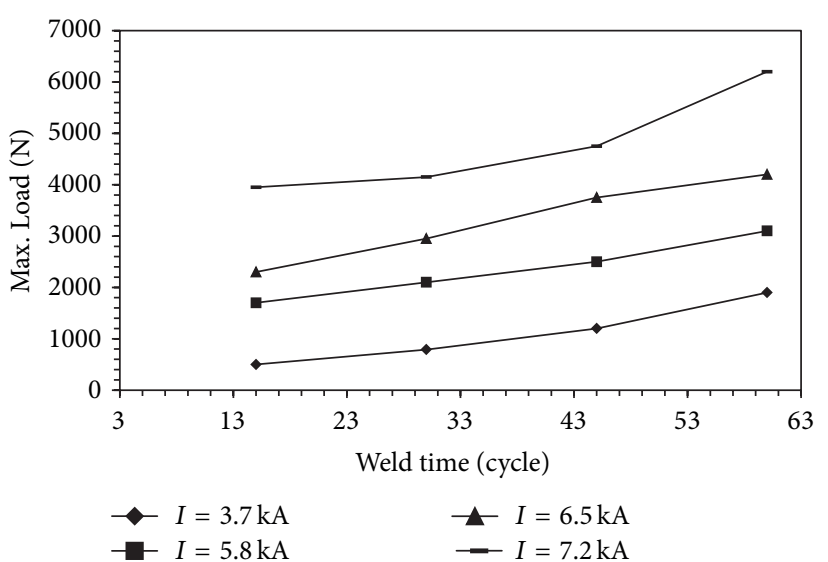

(a)

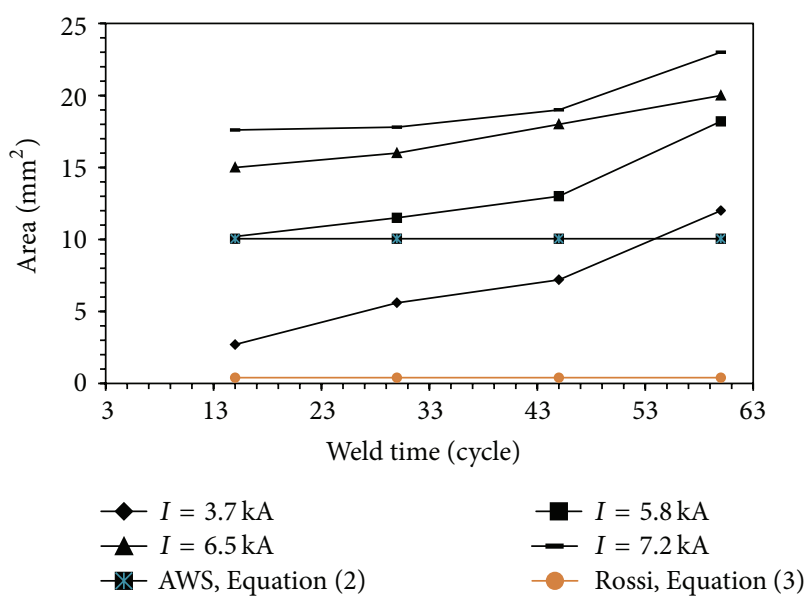

(b)

FIGURE 5: Effect of time of the peel joints; $d_{\mathrm{el}}=4 \mathrm{~mm}, t=0.8 \mathrm{~mm}$; (a) tensile strength; (b) weld nugget area.

\section{Conclusions}

Most published studies are dealing with the thickness more than $1 \mathrm{~mm}$. In this work, $0.8 \mathrm{~mm}$ carbon steel has been welded. Traditionally, the welding current has a major effect on the weld area and joint strength more than the weld time and electrode pressure. If the current is low, the weld joint will have insufficient strength due to the brittleness nature of the produced nugget. The spot welds strength depends upon the joint design. Therefore, the curved peel-joint has a lower strength as compared with the lap joint; however, the weld areas for the peel-joint are larger than those of the lap joint. A good correlation was obtained between tensile shear strength and weld nugget area. It finds that the weld strength proportion to the diameter of fused zones (weld nugget). The spot joint configuration has an effect on the heat dissipation. Therefore, the overlapped peel specimens have a higher nugget area, due to lower heat dissipation (higher heat built up) at nugget regions. The parameters that are not favorable for spot reliability are determined through Lobe curve. In this work, the spot weldability has been determined under different loading conditions. Therefore, a 


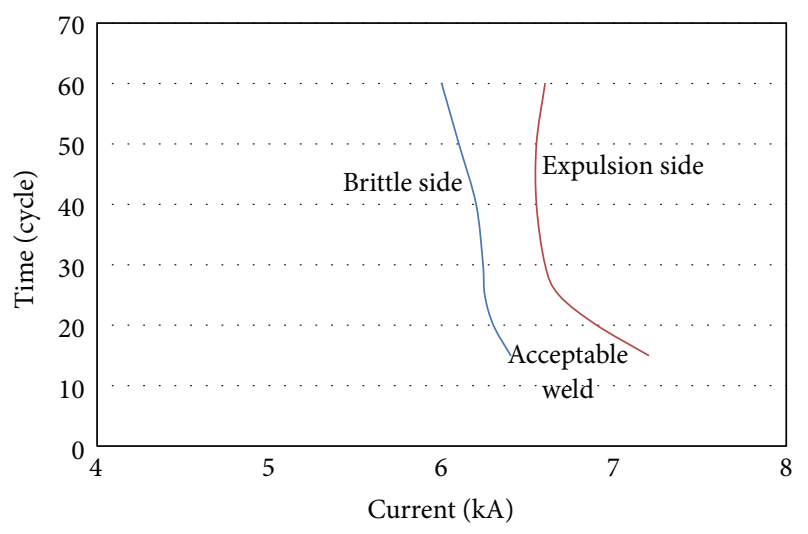

FIgURE 6: Lobe curve; $d_{\mathrm{el}}=4 \mathrm{~mm}, t=0.8 \mathrm{~mm}$, lap joint.

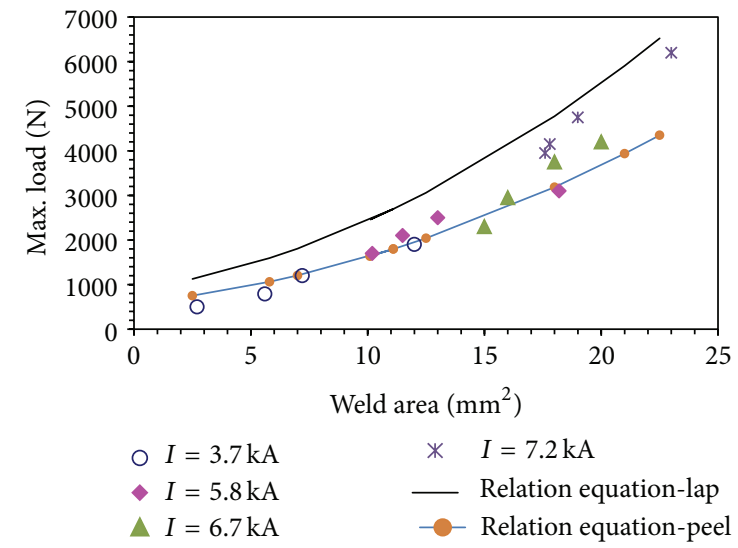

FIGURE 7: The relation between weld area and joint strength for lap and peel joints.

better reliability can be determined for specific materials. The minimum weld area that is needed for specific thickness was compared with the experiments results. Hence, the minimum weld area was determined as compared with AWS relation and experiments.

\section{Acknowledgments}

The first author would like to thankfully appreciate the support received from the Technische Universitaet Bergakademie Freiberg, Institute of Hydrology, Faculty of Geosciences and Geoengineering. The support from the Institute of International Education (IIE), USA, is gratefully appreciated.

\section{References}

[1] S. W. Gibson, Advanced Welding, Macmillan, London, UK, 1997.

[2] J. M. Sawhill Jr. and J. C. Baker, "Spot weldability of highstrength sheet steels," Welding Journal, vol. 59, no. 1, 1980.

[3] J. M. Sawhill Jr., H. Watanabe, and J. W. Mitchell, "Spot weldability of Mn Mo Cb, V-N and SAE 1008 steels," Welding Journal, vol. 56, no. 7, 1977.
[4] S. Aslanlar, A. Ogur, U. Ozsarac, E. Ilhan, and Z. Demir, "Effect of welding current on mechanical properties of galvanized chromided steel sheets in electrical resistance spot welding," Materials and Design, vol. 28, no. 1, pp. 2-7, 2007.

[5] N. Kahraman, "The influence of welding parameters on the joint strength of resistance spot-welded titanium sheets," Materials and Design, vol. 28, no. 2, pp. 420-427, 2007.

[6] D. Özyürek, "An effect of weld current and weld atmosphere on the resistance spot weldability of $304 \mathrm{~L}$ austenitic stainless steel," Materials and Design, vol. 29, no. 3, pp. 597-603, 2008.

[7] D. K. Aidun and R. W. Bennett, "Effect of resistance welding variables on the strength of spot welded 6061-T6 Aluminum alloy," Welding Journal, vol. 64, no. 12, pp. 15-25, 1985.

[8] D. R. Andrews, "The importance of monitoring resistance welding parameters," Welding and Metal Fabrication, vol. 54, no. 3, pp. 121-122, 1986.

[9] P. K. Ray and B. B. Verma, "A study on spot heating induced fatigue crack growth retardation," Fatigue and Fracture of Engineering Materials and Structures, vol. 28, no. 7, pp. 579-585, 2005.

[10] S. Aslanlar, A. Ogur, U. Ozsarac, and E. Ilhan, "Welding time effect on mechanical properties of automotive sheets in electrical resistance spot welding," Materials and Design, vol. 29, no. 7, pp. 1427-1431, 2008.

[11] A. W. Society, Welding, Welding Handbook, 4th Edition, Sec. (2), 1958.

[12] B. E. Rossi, Welding Engineering, McGraw-Hill, New York, NY, USA, 1954.

[13] J. Dufourny and A. Bragard, "Resistance spot welding of high strength low alloy steel (HSLA) sheet, a survey," Welding in the World, Le Soudage Dans Le Monde, vol. 23, no. 5-6, pp. 100-123, 1985.

[14] H. Moshayedi and I. Sattari-Far, "Numerical and experimental study of nugget size growth in resistance spot welding of austenitic stainless steels," Journal of Materials Processing Technology, vol. 212, no. 2, pp. 347-354, 2012.

[15] T. Uwaba, Y. Yano, and M. Ito, "Resistance spot weldability of $11 \mathrm{Cr}$-ferritic/martensitic steel sheets," Journal of Nuclear Materials, vol. 421, no. 1-3, pp. 132-139, 2012. 

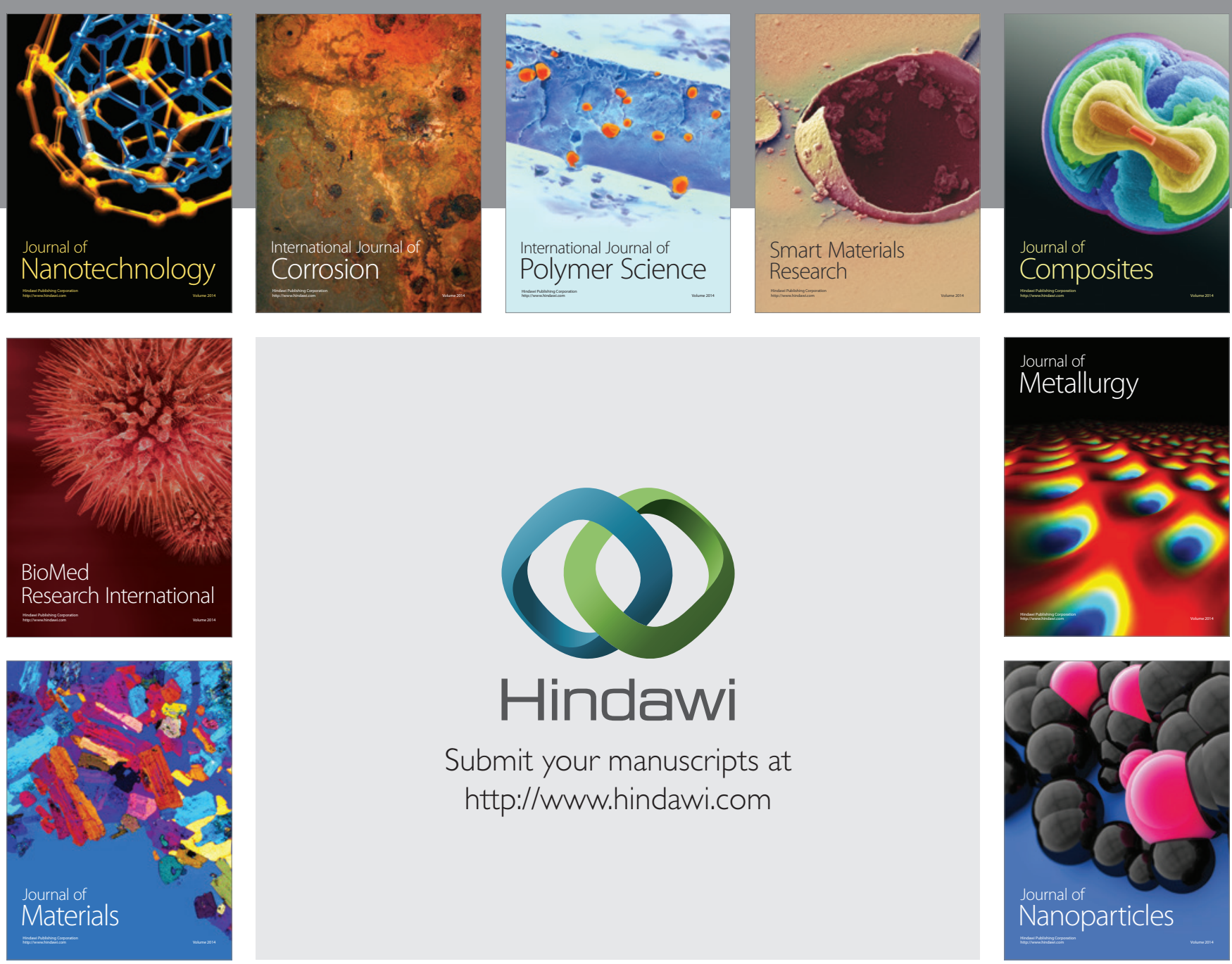

Submit your manuscripts at http://www.hindawi.com
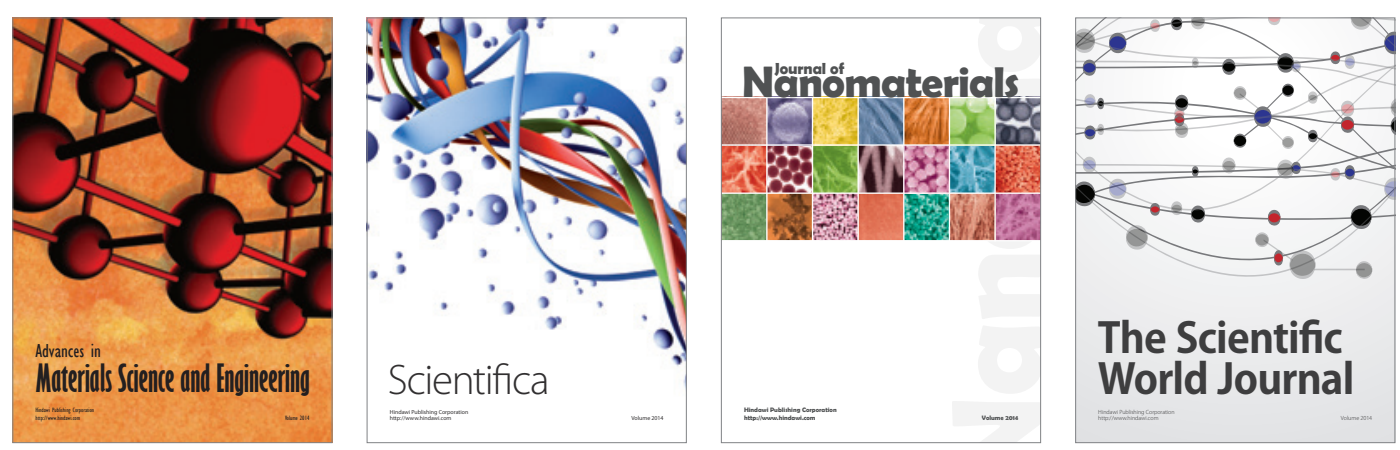

\section{The Scientific World Journal}
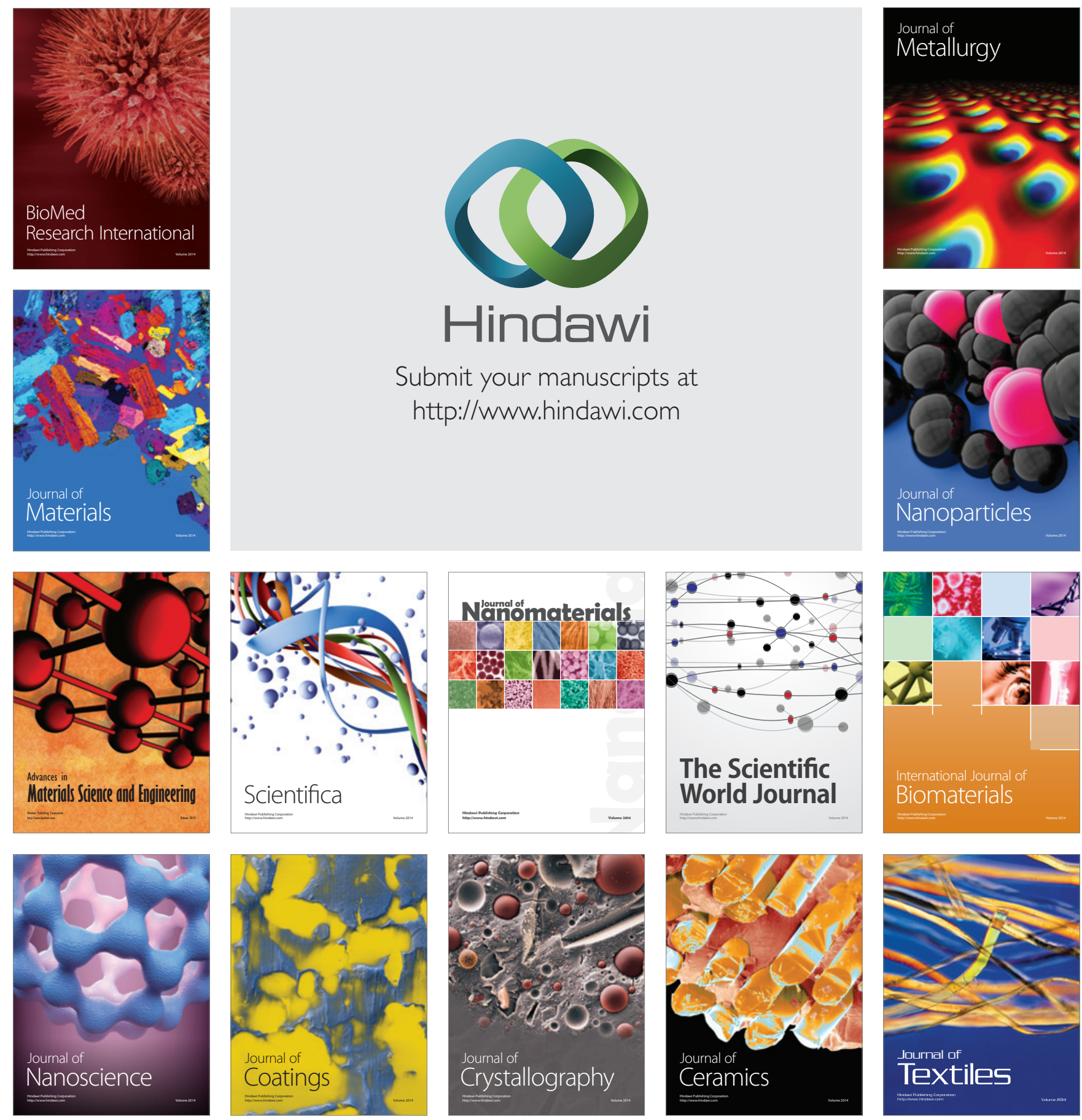